\title{
SYMMETRICAL CORTICAL NECROSIS OF THE KIDNEYS IN INFANCY AND CHILDHOOD
}

\author{
A. COLIN P. CAMPBELL, M.B., F.R.C.P.E., and \\ J. L. HENDERSON, M.D., F.R.C.P.E. \\ (From the Departments of Pathology and Child Life and Health, University of Edinburgh)
}

Symmetrical cortical necrosis of the kidneys is very uncommon. Apparently the first authentic description of the condition was given by JuhelRénoy in Paris in 1883, the patient being a young woman aged sixteen years. Since that time about one hundred cases have been published, most of them in the last twenty years. The disease is best known as a complication of pregnancy, but it may occur in non-pregnant women, males, and children; about two-thirds of the reported cases have been associated with pregnancy and many of the remainder with bacterial infection. Duff and More, who reviewed the literature up to 1941, analysed seventy-one cases, forty-eight associated and twentythree not associated with pregnancy; but Dunn and Montgomery, in the same year, published fifteen cases of which only seven were associated with pregnancy. The age distribution of cases not associated with pregnancy has been widely scattered through childhood, adolescence, and maturity, and there has not been any significant difference in the sex incidence in this group.

Records of only nine cases of bilateral cortical necrosis of the kidneys occurring in children under fifteen years of age have been found in the literature. The apparent rarity of the disease in childhood has induced us to review these cases and to record four more. Two of our cases occurred in infants, the patients being aged 9 weeks and $24 \frac{1}{2}$ weeks respectively. These are of particular interest since the disease has never before, to our knowledge, been reported in infancy. The fact that three of our cases were observed within a period of nine months, in a community of barely half a million inhabitants, shows that the disease is not as rare in infancy and childhood as the paucity of reports in the literature suggests.

\section{Case Records}

Case 1. E.D., a girl aged $10 \frac{1}{2}$ years, was admitted to the Children's Unit, Western General Hospital, Edinburgh, on Oct. 20, 1947, with a history of recurrent abdominal pain for two years. At first the pain had been felt at intervals of two to three weeks, but it became more frequent and latterly occurred at intervals of a few days. The attacks tended to be concentrated in groups and 'to be accompanied by fever.' The intensity of the pain became worse and latterly was very severe. It was centrally placed, had an aching character, and usually lasted a few hours. It developed at any time, but eating sometimes precipitated it, causing the child to be afraid to eat her meals. Vomiting had accompanied the pain on one occasion only. Loud borborygmi had been very troublesome in recent months. According to the mother there had not been any constipation or diarrhoea. The child had been losing weight in recent months and 'no longer plays and dances.' Her progress at school had become less satisfactory. The patient was a small, slender girl of poor nutrition who weighed only $48 \mathrm{lb}$. Skin tone was fair and muscle tone poor. The mucous membranes were healthy. She looked tired.

Almentary system. The mouth was healthy, the tongue clean and moist. The child indicated that the pain, when present, was periumbilical, and she complained of slight, indefinite tenderness in that region on palpation, but there was no muscular guarding and nothing abnormal was.palpated in the abdomen. Digital examination of the rectum was also negative. Radiological examination of the alimentary tract with a barium series revealed some dilatation of the lower ileum, also some narrowing and irregularity in the ileo-caecal region suggestive of ileo-caecal tuberculosis.

Respiratory system. Physical examination was negative. Radiological examination of the chest showed a few calcified glands at the left hilum, but the chest was otherwise normal.

CARDюvascular SYSTEM. A soft systolic murmur was heard in the mitral area.

HAEMOPOIETIC SYSTEM. No enlarged lymphatic glands could be palpated, and the spleen was not enlarged.

Blood examination gave the following results:

Haemoglobin, 80 per cent. (Sahli).

Erythrocytes, 5.02 million per c.mm.

Leucocytes, 7,000 per c.mm.

Differential count, normal.

Blood sedimentation rate (Westergren), $23 \mathrm{~mm}$. in one hour.

There was no abnormality in the urine. A Mantoux test $(1$ in 1,000$)$ was positive. 
During the first six days in hospital there was no abdominal pain, but constipation was troublesome, the bowels acting on alternate days and aperients being necessary.

On the seventh day severe lower abdominal pain with maximal intensity in the right iliac fossa suddenly developed. The constipation had been corrected before the onset of this pain and a normal motion was passed a few hours before it began. There was no vomiting. Digital examination of the rectum was negative. The temperature was not elevated. Leucocytes numbered 10,000 per c.mm.

The child was examined three hours after the onset of the pain by Mr. Mason Brown, paediatric surgeon, who immediately performed a laparotomy. Nitrous oxide and ether anaesthesia was used. A considerable amount of turbid free fluid was found in the peritoneal cavity and the mesenteric glands were enlarged and inflamed. The peritoneal exudate contained large numbers of polymorphs, scanty fibrin, serosal cells, and clumps of cocci, but there were no tubercle bacilli. The appendix looked normal and was removed: histologically it showed no abnormality, nor was there any evidence of tuberculosis. The wall of the terminal part of the ileum was congested and thickened and there was a partial obstruction near the proximal end of the abnormal segment of bowel. The omentum adhered to a grey, fibrinous patch on the wall of the ileum in the latter situation. The wall of the caecum was contracted and thickened and was bound to the posterior abdominal wall by adhesions. A diagnosis of ileo-caecal tuberculosis was made, and the obstruction towards the lower end of the ileum was short-circuited by an ileal anastomosis. Convalescence was satisfactory for thirteen days during which there was no further abdominal pain or constipation.

On the first day of the terminal illness nausea, vomiting, and diarrhoea developed fairly suddenly and the child looked pale and ill within a few hours. The stools contained mucus and were streaked with a little blood. Bacteriological examination of the stools did not reveal any organisms of the enteric or dysentery groups, and no tubercle bacilli were found in a direct film or on culture; the two guinea pigs inoculated died of intercurrent disease. The vomiting remained persistent and severe on the first day of the symptoms and there were four diarrhoeal stools. There was no fever. A provisional diagnosis of gastro-enteritis, possibly Sonne dysentery, was made and the patient was isolated. Small amounts of glucose water and dilute milk were given at frequent intervals, and a course of sulphamezathine (1 g. four-hourly) was begun.

Persistent vomiting continued during the second day, but there was only one stool (a.m.). The child looked very pale and ill. The leucocyte count had risen to 16,000 , the haemoglobin had fallen to 70 per cent., and the erythrocytes to $4 \cdot 2$ million. It was noticed that she did not void any urine after the morning of this day.
Vomiting persisted on the third day and the general condition had become worse. There was no further bowel movement. Complete anuria persisted. Catheterization of the bladder produced only a few $\mathrm{ml}$. of urine which contained a large amount of albumin, and, on microscopical examination, only a small number of erythrocytes. The temperature remained normal. The blood pressure was $115 \mathrm{~mm}$. $\mathrm{Hg}$ systolic and $70 \mathrm{~mm}$. $\mathrm{Hg}$ diastolic. Sulphamezathine was discontinued in the afternoon of this day after a total amount of $12 \mathrm{~g}$. had been administered in the previous forty-eight hours, of which a considerable, but unknown amount, had been ejected in the vomitus. On this day the child received $14 \mathrm{oz}$ of fluid orally and 1 pint of 5 per cent. glucose in normal saline intravenously.

On the fourth day complete anuria persisted and there was no further stool. Vomiting persisted. The blood pressure was slightly elevated, being $120 \mathrm{~mm}$. $\mathrm{Hg}$ systolic and $70 \mathrm{~mm}$. $\mathrm{Hg}$ diastolic. There was a generalized convulsion at 1.45 p.m. after which she remained unconscious and very restless with some spasticity of the limbs and athetoid movements of the hands. Lumbar puncture yielded clear cerebrospinal fluid under normal pressure. The only abnormality in the fluid was a slight increase of protein to $50 \mathrm{mg}$. per cent. The blood urea nitrogen had attained a high level on this day, being $130 \mathrm{mg}$. per cent. Six hours after the onset of unconsciousness the coma became deeper and the restlessness diminished. The blood pressure remained at its former level. The pulse rose in the evening to 140 per minute. There were no focal signs of nervous disease on examination of the superficial and deep reflexes and ocular fundi. On this day the child received one pint of 5 per cent. glucose in half-normal saline intravenously. Sodium sulphate, $200 \mathrm{ml}$. of a 4.8 per cent. solution, was then given intravenously followed by $50 \mathrm{ml}$. of a 50 per cent. glucose solution six hours later. To diminish the restlessness and muscular hypertonia, sodium phenobarbitone, $1 \frac{1}{2}$ gr., was given intramuscularly.

The child's condition continued to deteriorate on the fifth day with persistent anuria and coma. The pulse rate still rose, and the temperature for the first time reached $100^{\circ} \mathrm{F}$. There was one motion eight hours before death after a lapse of three days. The child died in the forenoon of this day, twenty hours after the beginning of coma. After the onset of unconsciousness $1 \frac{1}{2}$ pints of 5 per cent. glucose in a quarter normal saline had been given intravenously in addition to the sodium sulphate and hypertonic glucose.

NECROPSY (performed five hours after death). The body was that of a girl of slight build, rather poorly nourished. The abdomen showed a recent operation incision, healing satisfactorily.

The pleural sacs each contained about $100 \mathrm{ml}$. and the pericardial sac about $80 \mathrm{ml}$. of clear yellow transudate. The peritoneal sac contained only a few ml. of similar fluid. 
The upper lobe of the left lung and hilar lymph nodes showed an apparently quiescent primary tuberculous complex, with caseation, fibrosis, and calcification.

The peritoneal cavity showed fibrinous adhesions as the result of the recent operation, and in addition occasional old fibrous adhesions between loops of bowel and around the spleen; very occasional isolated small grey tubercles were present in the peritoneum of the small and large intestine. Four strictures with shallow transverse healing ulcers were found, three in the small intestine and one in the transverse colon. There was no appreciable distension of any part of the bowel. The uppermost of these stenosing ulcers, at the lower end of the jejunum, had been short-circuited by a recent, healthily healing, side-to-side anastomosis. The appendix had recently been removed. The lower three feet of the ileum showed uniform intense congestion and swelling of the mucosa, with semiconfluent haemorrhages, and a fibrinous exudate on the peritoneum. The mesenteric lymph nodes were considerably swollen, soft, and of a uniform dusky red appearance on section; they showed no sign of tuberculosis.

The kidneys were of identical appearance. They were slightly swollen, the subcapsular surface was smooth but considerably congested, and thickly studded with tiny haemorrhages. On section, cortex and medulla were both uniformly congested, and the cortex was studded with petechiae throughout. The consistence was slightly softened. The bladder was empty.

The liver showed cloudy swelling.

Brain and meninges, mouth, neck organs, heart, aorta, stomach and duodenum, bile passages, pancreas, suprarenals, spleen, uterus, ovaries, and bone marrow all appeared normal.

On histological examination both kidneys showed the same picture of severe cortical damage (fig. 1). The glomeruli were almost all affected, though in varying degree; there was great dilatation of the capillary loops, though not necessarily of all the loops of any individual tuft; most of the dilated loops contained uncoagulated red cells, but a large minority was plugged by eosinophil homogeneous or fibrillar material which gave the staining reactions of fibrin; sometimes these fibrin thrombi did not completely occlude the lumina, but formed crescentic or ring-like mural deposits. The most severely damaged glomeruli showed karyorrhectic necrosis of all the cells; those less damaged showed considerable swelling and proliferation of the epithelium covering the tuft, and slight swelling (but no proliferation) of the capsular epithelium. Both capsular and tuft epithelial cells showed colloid droplet degeneration. The capillary endothelium of the less severely damaged glomeruli showed a little swelling in some loops. In many glomeruli the capsular space contained free red cells.

Most of the cortical tubules showed patchily distributed coagulative necrosis. Areas where every tubule was necrotic alternated with areas where the necrosis was limited to the proximal convoluted tubules; the ascending limbs of Henle's loops, the distal convoluted tubules, and the collecting tubules were spared. The areas of severest tubular damage coincided with those where the glomerular changes were most marked. In the least damaged areas some of the proximal tubules had escaped necrosis. They showed various degenerative changes, however: cloudy swelling, a good deal of colloid droplet degeneration, and occasionally considerable dilata

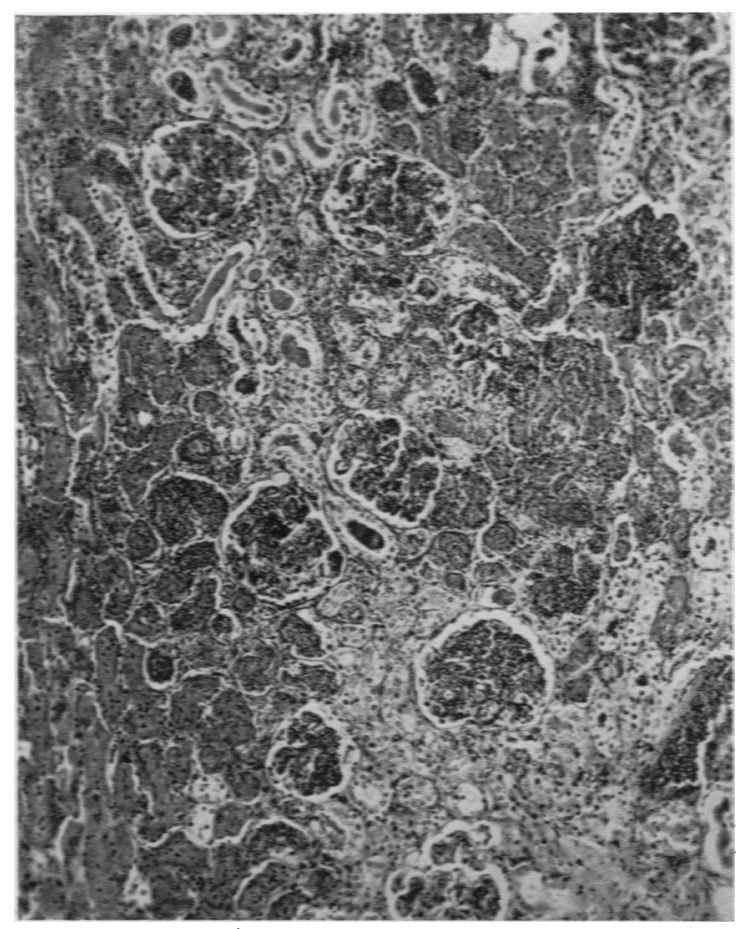

Fig. 1.-Photomicrograph of renal cortex (Case 1), showing characteristic great glomerular congestion and extensive patches of tubular necrosis (darkly stained areas). Haematoxylin and cosin. $\times 70$.

tion. Some of the tubules contained red cells, others necrotic epithelial debris, polymorphs or hyaline material.

These glomerular and tubular changes showed a tendency to zonal variation; a narrow subcapsular zone, and a wider zone in the juxtamedullary cortex were relatively sparse.

The tissue was nowhere completely necrotic; even where every tubule showed necrosis of its epithelium the interstitial cells survived. Nor was there any sign of thrombosis in the intertubular capillaries. The more severely damaged areas showed a good deal of polymorph infiltration of the interstitium as well as of the necrotic tubules. 
The medulla showed little abnormality; the tubules contained casts (mainly hyaline, occasionally granular), but their epithelium appeared healthy.

Apart from the glomeruli the blood vessels showed little abnormality; fibrin thrombosis extended back from a few of the glomeruli into the terminal parts of their afferent arterioles, and a few other afferent arterioles, which were not thrombosed, showed red cells, and a little fibrin in their walls. Other afferent arterioles appeared slightly dilated but otherwise normal. The interlobular arteries showed slight dilatation, but no

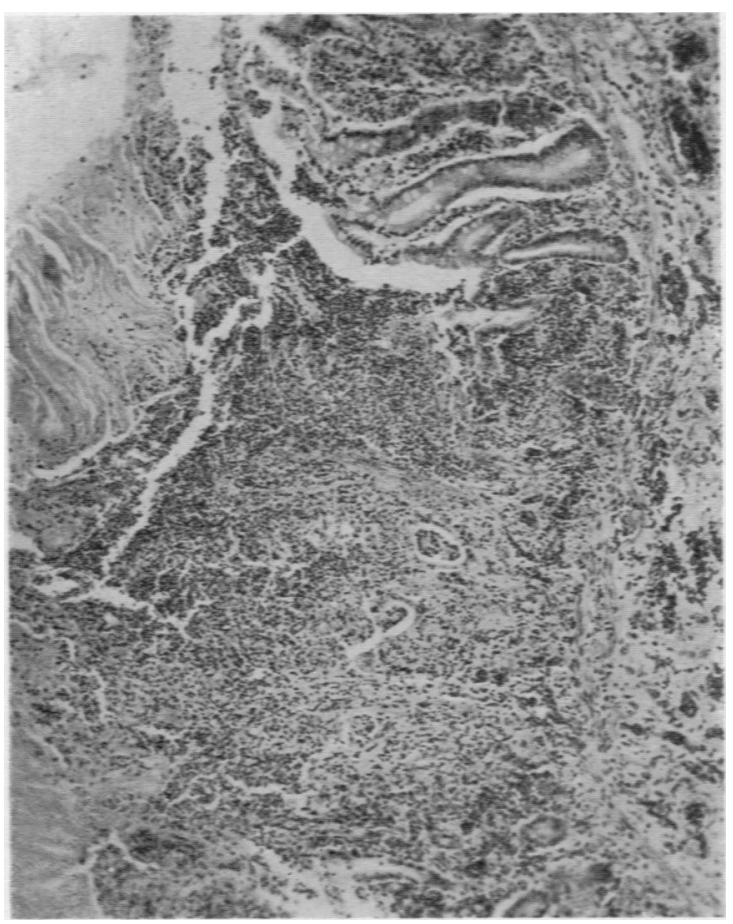

FIG. 2.-Photomicrograph of ileum (Case 1), showing patch of necrosis of mucosa, and oedema, congestion, and haemorrhage in the submucosa. Haematoxylin and eosin. $\times 70$.

thrombosis, intramural haemorrhage or fibrin deposition. The arcuate arteries were normal. The interlobular veins were considerably dilated, but showed no other change. The cortical intertubular capillary bed was moderately congested and the vasa recta of the medulla were markedly so, but no thrombosis was seen in either.

Sections of the ileum from the area of haemorrhagic enteritis showed great congestion of mucosa and submucosa, but the muscular and subserous coats appeared normal. The submucosa was very cedematous; the mucosa showed semi-confluent haemorrhage, and many small patches of coagulative necrosis (fig. 2); there was on the surface a fibrinpolymorph exudate, adherent to, and apparently emanating from the necrotic patches; polymorph infiltration, however, was not generalized. Some of the necrotic patches showed little or none. There was no ukceration. The capillaries and venules of the submucosa were greatly congested, and some of the venules were plugged by thrombi of mixed fibrin-platelet type. The arterioles varied in calibre from contraction to moderate dilatation; many showed fibrinoid infiltration of the intima, but only rarely thrombosis.

A section from one of the stenoses showed healed ulceration; a depression of the mucosal surface, covered by regenerated mucosa, deep to which there was scar tissue formation replacing the inner muscle coat. There was no sign of active tuberculosis.

A mesenteric lymph node showed congestion and some polymorph infiltration. It contained an old encapsulated caseous area but there was no sign of active tuberculosis.

The lungs showed mild acute bronchitis.

The appendix (removed at operation), and the liver, spleen, pancreas, and suprarenals showed no significant abnormality.

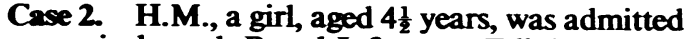
to a surgical ward, Royal Infirmary, Edinburgh, on Feb. 17, 1938, with a history of recurrent tonsillitis and cervical adenitis for one year. Tonsillectomy was performed twelve days before admission to hospital. The child seemed to recover well from the operation but the enlarged cervical glands on the left side became larger. Three days before admission she developed pain in the right hip. The pain was worse the following day and there was obvious fever. Pain, fever, and disturbed sleep continued until admission. There is no record of urinary symptoms.

On examination, development and nutrition were considered satisfactory. Movements at the right hip joint were restricted, and external and internal rotation were painful. There was tenderness on firm palpation over the head of the femur. No other abnormalities were recorded.

A radiograph of the right hip joint taken the day after admission showed:

\begin{abstract}
- Joint space slightly widened with probable distension of the joint capsule and slightly increased density of the soft tissue shadows around the joint. The appearance is consistent with early acute arthritis."
\end{abstract}

The temperature reached $103 \cdot 8^{\circ} \mathrm{F}$. on the day after admission, varied between $99.0^{\circ} \mathrm{F}$. and $101.0^{\circ} \mathrm{F}$. on the three following days, and thereafter never exceeded $99 \cdot 4^{\circ} \mathrm{F}$. Diarrhoea developed five days after admission and the child passed nine stools that day. Drowsiness and slight head retraction were also observed on the same day. Less severe diarrhoea persisted for the following two days. There is no record of melaena. 
Dysentery was suspected but bacteriological examination of the stools did not reveal any pathogens.

The drowsiness and head retraction became worse. Internal strabismus developed four days after the beginning of these signs. Lumbar puncture was unsuccessful. A fatal epileptiform seizure occurred at $12.30 \mathrm{p} . \mathrm{m}$. On the same day, nine days after admission and four days after the onset of diarrhoea.

There is no record of the frequency of micturition or of urine examination.

NECROPSY (performed forty-six hours after death). The body was that of a well developed, well nourished child.

The right hip joint contained thick pus, from which a haemolytic streptococcus was isolated.

The kidneys were of normal size, and of identical appearance. In each the subcapsular surface was congested and thickly studded with small haemorrhages. On section the cut surface showed great congestion, with many small haemorrhages throughout the cortex.

The large intestine showed a segmental lesion affecting the whole of the pelvic colon; the wall of this segment was greatly swollen by haemorrhagic oedema affecting the entire thickness; the serous surface showed a localized fibrinous peritonitis. The appearance suggested haemorrhagic infarction from inferior mesenteric artery thrombosis, but no such thrombosis was found.

The brain showed moderate congestion of the lepto-meninges, and very slight flattening of the cerebral gyri. A haemolytic streptococcus was isolated from the basal cerebrospinal fluid.

The spleen showed slight softening and congestion of the pulp, without obvious enlargement, and the liver and myocardium cloudy swelling. The other organs showed no significant abnormality.

On histological examination of the kidneys the following changes were seen throughout the several sections examined. Almost every glomerulus was affected, showing either great congestion or, in many cases, fibrin thrombosis of the capillary loops; some capillaries showed a tubular layer of fibrin with a still patent lumen. Some of the fibrin thrombi stained diffusely with Scharlach R. Occasional glomeruli were completely necrotic. Extravasated red cells were seen in the capsular spaces of a few glomeruli (occasionally accompanied by fibrin) and in a few convoluted tubules, both proximal and distal. The less severely damaged glomeruli showed slight swelling and a little fatty degeneration of the visceral epithelium. The subcapsular glomeruli were slightly, and the juxtamedullary glomeruli considerably, less severely affected. Tubular changes were confined to the proximal convoluted tubules; complete necrosis was seen only in occasional small groups; many others, however, showed nuclear pyknosis with necrosis and granular disintegration of individual cells. Many of the less affected tubules showed marked colloid droplet degeneration, others only cloudy swelling or post-mortem change.
The interstitium of the cortex showed a profuse, semi-diffuse polymorph infiltration, which was not confined to the neighbourhood of the foci of frank tubular necrosis. There were occasional interstitial haemorrhages.

The afferent arterioles were dilated. Many showed infiltration of red cells and sometimes fibrin into their walls. Some were occluded by fibrin thrombi. The interlobular arteries showed only slight dilatation. The arcuate arteries appeared normal.

The medulla showed marked congestion of the vasa recta, but was otherwise normal.

The entire wall of the pelvic colon was grossly oedematous and heavily infiltrated by red cells. Post-mortem change prevented further analysis.

The spleen showed a banal acute infective reaction.

The liver, lung, and myocardium showed no significant abnormality. Sections of the brain were not available.

Case 3. J.W., a girl, aged $5 \frac{1}{2}$ months at death, was admitted to the Gastro-enteritis Unit, City Fever Hospital, Edinburgh, on July 17, 1948, with a history of vomiting and diarrhoea for six days. The baby had been well until six days before admission when she began to sneeze and cough and to vomit after each feed. The same night the stools became loose and 'blackish-green with blood among them.' The milk feeds were stopped and glucose water given. The vomiting ceased at the end of the second day, but the stools remained loose and interspersed with a considerable amount of blood. Moreover she had 'bouts of crying as if in pain.' During the first three days of the illness she continued to feed fairly well, did not seem feverish, and looked only slightly ill. Pink staining of the napkin was noticed during this phase, but it was not possible to determine from the history whether this was caused by melaena, which was definitely present, or by haematuria, which may have been present, particularly in view of the later history, or by both.

After three days of illness the baby was taken to the Medical Out-Patient Department at the Royal Hospital for Sick Children, Edinburgh, where a diagnosis of acute gastro-enteritis was made. She did not look unduly ill. A loose yellow stool without visible blood was seen on the napkin but no pink urine staining was observed. She was treated at home for the next three days on a diluted milk mixture with sulphaguanidine, $0.5 \mathrm{~g}$., four times a day. She then returned to the Medical Out-Patient Department where her general condition was found to have deteriorated, though she did not appear to be very ill. Vomiting had occurred after most feeds for the last two days. Diarrhoea had persisted with four or five loose green stools per day.

On admission to hospital the patient was seen to be a well developed, well nourished baby, weighing $14 \mathrm{lb}$. The skin and conjunctivae were pale. She looked alert and was not unduly fretful or dehydrated. The mouth was rather dry and the 
tongue was slightly furred. The buttocks were excoriated on each side of the natal cleft.

During the first day in hospital the stools were frequent, dark brown, and watery, with mucus, and, sometimes, a trace of blood. No enteric or dysentery organisms were isolated from them. Vomiting was also frequent, the vomitus being clear fluid containing traces of coffee-ground material and a little mucus. During the remainder of this day Hartmann's solution was given by mouth and no drugs were given. By the second day the infant's

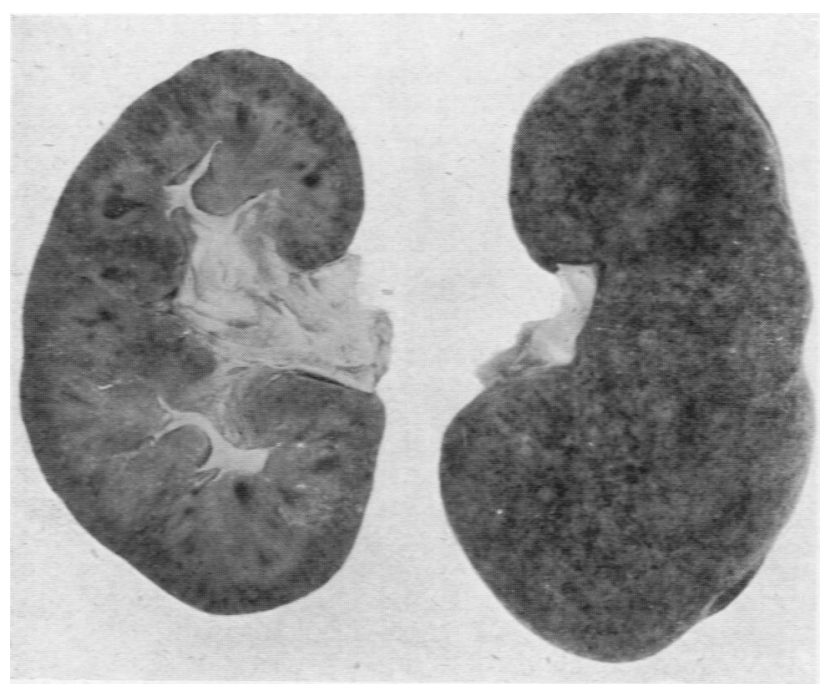

Fig. 3.-Photograph of kidney (Case 3) showing cortical congestion and numerous small hacmorrhages with sparser larger haemorrhages in the medulla.

general condition had deteriorated. She fed reluctantly and the pallor had increased. The diarrhoea and vomiting continued and the vomitus, which still contained coffee-ground material, had now become bile-stained. Alarm was felt at the child's failure to pass any appreciable quantity of urine since admission on the previous day, although a small pinkish stain on the napkin, thought to have been caused by urine, was seen on four occasions within the first twenty-four hours after admission. Catheterization was carried out several times but no urine was obtained. A slight degree of generalized oedema was noticed, particularly in the face.

Blood examination gave the following results;

Haemoglobin, 38 per cent. (Sahli); erythrocytes, 1.6 million per c.mm.; leucocytes, 24,600 per c.mm.; reticulocytes, 16 per cent.; urea nitrogen, $265 \mathrm{mg}$. per cent., an extremely high figure.

Slight generalized muscular twitchings were observed at 6.30 p.m. By evening so little fluid had been retained and so much lost in the diarrhoeal stools that, in spite of the lack of apparent dehydration, an intravenous drip was begun.
Half-strength Hartmann's solution containing 5 per cent. glucose (1 oz per hour) was given for three and a half hours followed by whole blood $\left(\frac{3}{4} \mathrm{oz}\right.$. per hour) for three hours. The general condition steadily deteriorated. Penicillin, 100,000 units intramuscularly four-hourly, was given on this, the last day of the illness.

Death occurred at 2 a.m. on July 19, 1948.

NECROPSY (performed nine hours after death). The body was that of a well developed, well nourished infant. The skin was pale. No pitting oedema was found, but the subcutaneous tissue generally was very wet.

The pleural and pericardial sacs each contained about $50 \mathrm{ml}$. and the peritoneal cavity about $100 \mathrm{ml}$. of clear yellow transudate.

The only organs showing gross abnormality were the kidneys. These were of identical appearance (fig. 3); they were considerably swollen; the subcapsular surface was smooth, congested, and stippled with tiny haemorrhages; on section, both cortex and medulla were greatly congested, swollen and soft; the cortex showed numerous tiny petechiae, and the medulla fairly frequent, considerably larger, haemorrhages. No focal areas of infarction were seen. The pelves appeared healthy. The bladder was empty.

The lungs showed considerable oedema and hypostatic congestion. The myocardium and the liver were pale.

The bone marrow of the middle of the shaft of the femur appeared of the uniform red colour to be expected at this age.

Brain and meninges, middle-ear cavities, mouth, neck organs, stomach and bowel, biliary passages, pancreas, suprarenals, spleen, uterus, tubes, and ovaries all appeared normal.

On histological examination both kidneys showed a picture basically identical with that seen in Case 1; great engorgement and thrombosis of glomeruli with patchy necrosis of cortical tubules (fig. 4). Nearly all the glomeruli showed great congestion of some or all of their capillary loops, and many loops were occluded by fibrin thrombi. In some cases a part or the whole of the glomerulus was fused into a fibrinoid necrotic mass. In the less damaged glomeruli there was swelling and proliferation of the tuft epithelium and some of the cells showed eosinophil colloid droplet degeneration; a few glomeruli showed capsular 'crescent 'formation. The capillary endothelium showed swelling, fatty degeneration and proliferation in some glomeruli; some capillary loops were (in contrast to the majority) ischaemic through this proliferation. These proliferative changes were most marked in the juxta-medullary glomeruli, which tended to be less severely affected than the others.

The tubular necrosis was, as in Case 1, patchy 
and limited to the cortex; some patches showed complete infarction, the interstitial cells as well as the tubular epithelium being necrotic; other patches showed necrosis of all the tubules with survival of the interstitium, whereas in others only the proximal convoluted tubules were necrotic. Proximal tubules which had escaped necrosis showed colloid droplet change and fatty degeneration. There were many glomerular haemorrhages, extending into the corresponding proximal tubules. Red cells were seen also in many loops of Henle and distal convoluted tubules, but only occasionally in collecting tubules.

The patches of necrosis were much more sparsely placed than in Case 1, although the glomerular lesion was equally severe. It was noticeable that tubular necrosis occurred, especially in those areas where the ratio of volume of glomerular to tubular tissue approached that of the adult kidney; areas where the relative underdevelopment of tubular tissue, characteristic of the infantile kidney, was marked, tended to escape tubular necrosis.

The medulla showed no necrosis. Many tubules contained casts, mainly hyaline. There were occasional interstitial haemorrhages.

Many afferent arterioles were plugged by fibrin thrombi, apparently extending back from the associated glomeruli; occasionally the thrombosis extended back into an interlobular artery. Some afferent arterioles and interlobular arteries showed fatty degeneration of the muscle and endothelium, and fibrinoid infiltration of the intima, or even fibrinoid necrosis of the wall. This change was seen sometimes without thrombosis of the vessel. These vessels were not appreciably dilated. The larger arteries and veins appeared normal. There was no thrombosis of vessels in the medulla.

Slight polymorph infiltration was seen in some of the necrotic foci.

There was a little fatty degeneration in the liver, indiscriminately distributed through the lobules. There was no necrosis or vascular thrombosis.

The small intestine was normal.

Marrow from the middle of the shaft of the femur showed congestion and gross hypoplasia with a normal erythroid : leukoblastic ratio. Plasma cells were considerably increased.

Sections of the spleen, lung, myocardium, pancreas, and suprarenal showed no abnormality.

Case 4. G.P., a male infant., aged nine weeks (61 days) at death, was admitted to the Gastroenteritis Unit, City Fever Hospital, Edinburgh, on Feb. 17, 1948, with a history of vomiting for fourteen days and diarrhoea for nine days.

This infant was born in the Simpson Maternity Hospital, Edinburgh, on Jan. 5, 1948, of an unmarried mother. (Birth weight, $7 \mathrm{lb} .1 \mathrm{oz}$.) $\mathrm{He}$ progressed satisfactorily for four weeks. Two weeks before admission he began to vomit after feeds. Diarrhoea began five days later. One week before admission to hospital the feeding was changed from fresh cows' milk to National Dried Milk. The weight, which had stood at $7 \mathrm{lb} .3 \mathrm{oz}$. for a fortnight, fell $11 \mathrm{oz}$ in the last week before admission.

After two weeks of illness the infant was taken to the Medical Out-Patient Department at the Royal Hospital for Sick Children, Edinburgh, where he was found to be in a marasmic state, and was then admitted to the Gastro-Enteritis Unit at the City Fever Hospital.

On admission the infant was slightly toxic looking,

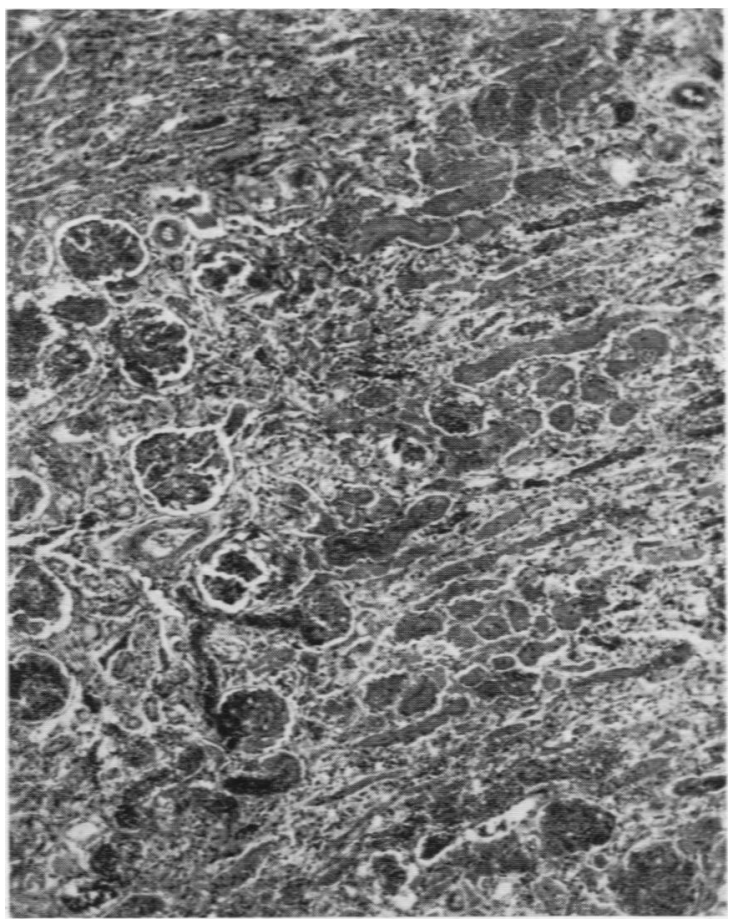

Fig. 4.-Photomicrograph of renal cortex (Case 3) showing glomerular congestion and thrombosis, thrombosis of two afferent arterioles, and several patches of tubular necrosis (dark staining). Haematoxylin and eosin. $\times 70$.

and weighed $6 \mathrm{lb} .15 \mathrm{oz}$. Skin hydration was fair. The eyes were not sunken, nor was the anterior fontanelle depressed. The mouth was clean and moist. The ears looked healthy. Nothing abnormal was found in the chest or abdomen.

On the first day in hospital there was occasional vomiting and the stools were green and watery. Urine was passed freely. Gastric lavage yielded clear fluid with a little mucus. Hartmann's solution, half-strength, $3 \mathrm{oz}$, three-hourly by mouth, was given, and also potassium citrate, gr. 5 , and sulphadiazine $0.25 \mathrm{~g}$., four-hourly.

On Feb. 18, 1948, the general condition was fair. 
Oedema of the eyelids was noticed. Urine examination showed:

No albumin; no cells; film, no organisms seen; culture, scanty growth of B. Proteus.

A rectal swab did not grow any pathogens.

On Feb. 19 the vomiting had ceased and the stools were reduced in number and were firmer in consistence. The oedema was worse and had spread to the hands and feet. The abdomen had become distended and cyanosis of the trunk and lower limbs had developed. Urine was still being passed freely; it did not contain albumin and the chloride content was 2 g. per litre. A rectal swab did not grow any pathogens. A very dilute 'special Cow and Gate half-cream' feed was begun, also 'betaxan' vitamin B complex, $1 \mathrm{ml}$. intramuscularly, daily.

On Feb. 20 the general condition was fair, and feeding satisfactory. A rectal swab did not grow any pathogens.

On Feb. 21 the oedema had become worse. There was considerable pitting, even over the front of the chest, and the extremities were swollen and blue. Urine was being passed but the amount was not estimated.

On Feb. 23 urine examination (catheter specimen) showed:

Film, no pus cells, a few Gram-positive cocci ; culture, a scanty growth of enterococci.

The general condition remained unchanged until Feb. 25, when the breathing became rapid and laboured. The temperature reached $99 \cdot 8^{\circ} \mathrm{F}$. after having been slightly elevated on the previous day, but by Feb. 26 the temperature had returned to normal. The oedema had subsided. The infant weighed $6 \mathrm{oz}$ less than on admission. Sulphadiazine was stopped after $15 \mathrm{~g}$. had been given over a period of nine days. 'Betaxan' was also discontinued.

On Feb. 27 the infant continued to feed well, but the stools had again become loose and rather frequent. The infant had lost $1 \mathrm{lb}$. over the last four days. There was no evidence of infection. The ears appeared to be healthy.

On Feb. 29 a moderate degree of oedema had returned.

On Mar. 1 the infant was feeding well, and passing urine. The oedema was unchanged. The ears appeared healthy. By Mar. 3 the oedema had subsided, but the weight was $\frac{1}{2} \mathrm{lb}$. less than a week earlier when there was no oedema. The infant continued to pass urine. A cough had developed.

The Half Cream Dried Milk was discontinued and replaced by breast-milk and 5 per cent. glucose water in equal parts, with the addition of half a drachm of 'hepovite' to each feed of $3 \frac{1}{2} \mathrm{oz}$ given threehourly. But on Mar. 5 general deterioration had occurred. The infant continued to pass urine. The temperature, which had been steadily rising for three days, reached $100 \cdot 4^{\circ} \mathrm{F}$. The ears appeared healthy. An intravenous drip of plasma and 5 per cent. glucose in equal parts was begun, also penicillin 50,000 units six-hourly and sulphadiazine $0.25 \mathrm{~g}$. four-hourly. On the following day the general condition had deteriorated rapidly. The temperature remained at $100^{\circ} \mathrm{F}$. and the child was gravely ill. The abdomen had become distended and the liver was enlarged to three finger-breadths below the costal margin. Jaundice was observed in the evening. The last nursing record of the passage of urine was at 10 a.m. It was probably impossible to distinguish between urine-staining of the napkin and that caused by the loose yellow stools passed on this and the previous day, so it was not possible to be sure when urine was last passed. Pink staining of the napkin attributable to urine was not recorded on any occasion.

Death occurred at 12.10 a.m. on Mar. 7, 1948.

NECROPSY (performed thirty-nine hours after death). The body was that of a male infant, slightly undersized, and considerably wasted. The skin showed moderate jaundice, but no petechiae. The fontanelle was sunken, but there was slight oedema of the dorsum of hands and feet. The serous sacs contained no excess of free fluid.

The small intestine showed mucosal petechiae, very sparse in the upper part, but fairly numerous in the lower ileum. The colon showed slight congestion and oedema of the mucosa, with occasional small petechiae.

The liver was slightly pale.

The left middle-ear cavity contained thick yellow pus, smears of which showed organisms resembling pneumococci and coliform bacilli; culture yielded Bact. coli only.

The lungs showed numerous pleural petechiae; the posterior parts of both lower lobes showed congestion, slight oedema, and a fine nodularity indicating early bronchopneumonia.

The heart showed numerous epicardial petechiae, and occasional petechiae within the substance of the left ventricular myocardium.

The kidneys were of identical appearance: they were moderately swollen and soft, the cortex tending to tear on stripping the capsule; the surface was smooth and pale, with scanty petechiae; on section, the cortex was swollen, pale, and sparsely studded with tiny petechiae; the outer zone of the medulla also appeared pale.

The other organs appeared normal.

Histological examination of both kidneys showed the same picture (figs. 5 and 6). The most striking changes were in the glomeruli, almost every one of which was involved; they showed gross dilatation of their capillary loops, some by close-packed red cells, and some by fibrin thrombi. The lesion appeared to be an early one; there was no sign of necrosis of the glomerular cells, nor was there any endothelial or epithelial proliferation or swelling, or polymorph infiltration. Many of the afferent arterioles were also affected, showing dilatation and profuse infiltration of red cells into their walls; a few were plugged by fibrin thrombi. The larger 
vessels appeared normal. The tubules showed very much less severe changes than in Cases 1 and 3. Apart from cloudy swelling (difficult to assess in

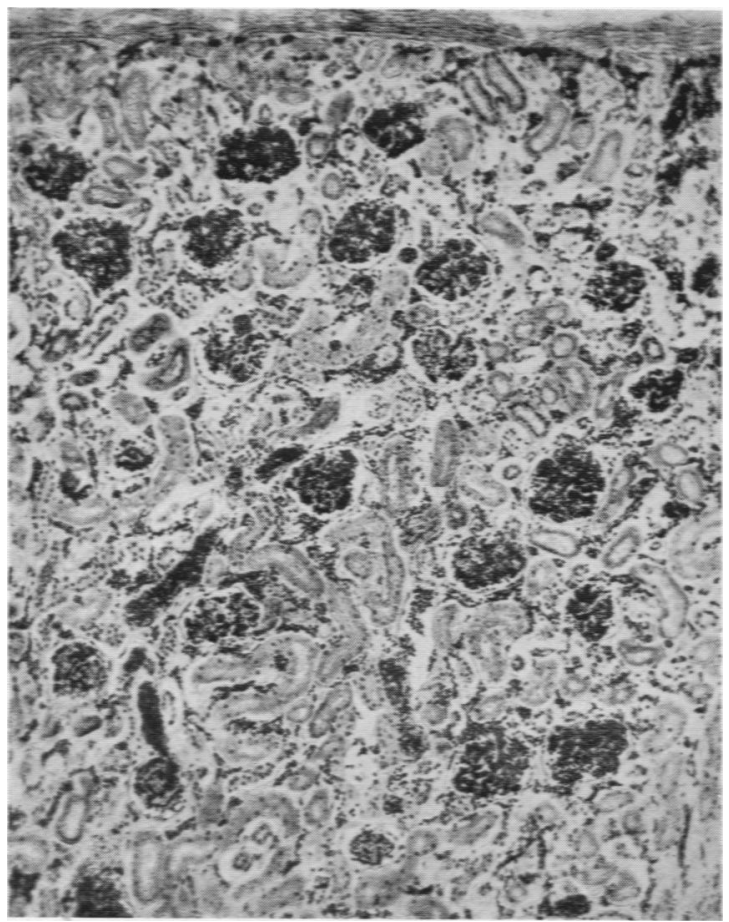

Fig. 5.-Photomicrograph of renal cortex (Case 4) showing great glomerular congestion and thrombosis. The fibrin thrombi appear black and the red cells almest black. Phosphotungstic acid haematoxylin. $\times 70$.

view of the long interval between death and necropsy) there was hyaline droplet change in some of the proximal convoluted tubules, and occasional small groups of these tubules showed early coagulative necrosis. There were, rather remarkably, no red cells in capsular spaces or tubular lumina. The interstitial tissue of the cortex showed oedema and occasional small haemorrhages. The medulla appeared normal.

The liver showed occasional small areas of focal necrosis, haphazardly located in the lobules. There was some histiocytic proliferation in these foci.

In the small and large intestine there were a few small mucosal haemorrhages, but no inflammatory changes.

The lower lobe of the lung showed acute bronchiolitis and early bronchopneumonia, with a little patchy collapse.

The mesenteric lymph nodes, spleen, pancreas and myocardium showed no significant abnormality.
Summary of the Pathological Changes in the Kidneys

The renal lesion appears to be of the same type in the four cases, varying only in degree and age. It is symmetrical renal cortical necrosis, or, as it has been called by Dunn and Montgomery (1941), acute necrotizing glomerulonephritis. The essential change appears to consist of vasostasis in the glomeruli, followed by ischaemic necrosis of the cortical tubules, and to a varying degree of the interstitial tissue also, produced by the failure of their blood supply from the efferent arterioles. Sometimes large patches of complete necrosis of all elements of the cortex may be seen. In other cases or in other parts of the same kidney the necrosis may be limited to the tubular epithelium, or may be still more limited, affecting only the proximal convoluted tubules (that part of the kidney tissue which is most vulnerable to ischaemia, as can be seen at the margins of the ordinary embolic infarct). None of the cases showed the classical macroscopic picture of patches of frank yellow infarction of the cortex. It is, however, well recognized that this is not constant, and in Cases 1 and 3 the microscopic picture entirely conformed to established criteria. In both, cortical tubular necrosis was extensive. The diagnosis of

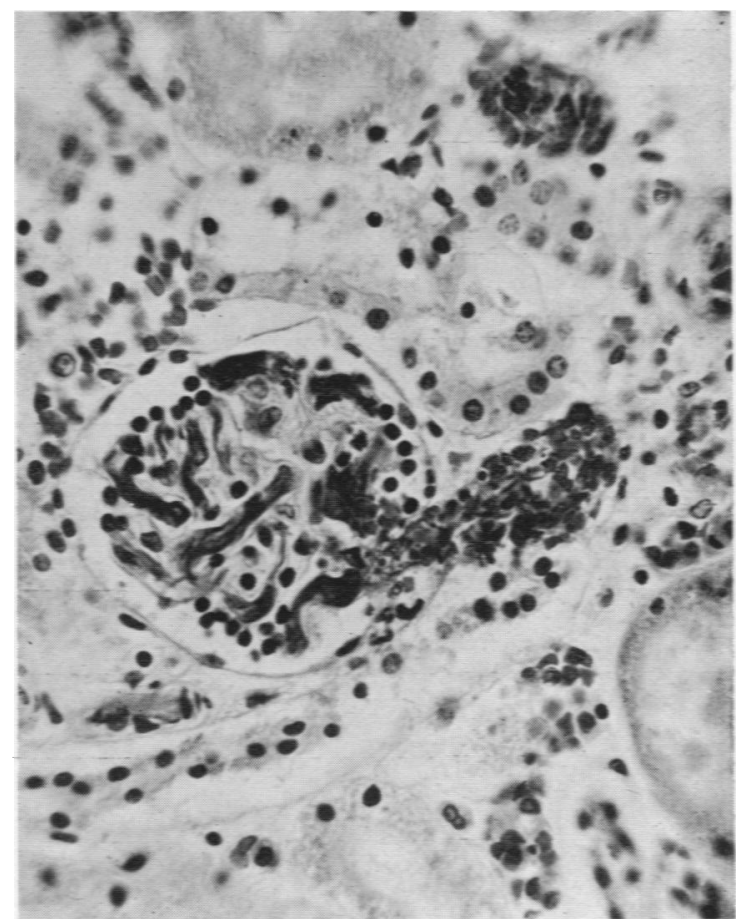

FIG. 6.-Photomicrograph of same section of renal cortex as in Fig. 5, showing in detail a typical glomerulus with capillaries blocked by fibrin thrombi. Note the infiltration of red cells into the wall of the afferent arteriole. Phosphotungstic acid haematoxylin. $\times 400$. 
renal cortical necrosis is not as obviously justified in Cases 2 and 4 where there was much less tubular necrosis. But in Case 4 at any rate this may. well be due to the cortical ischaemia being of too short a duration to have produced histologically appreciable necrosis in many tubules. If we accept cortical vasostasis as the prime factor in the production of the lesion, the evidence of widespread glomerular stasis in Case 4 justifies the inclusion of this case in the same category as Cases 1 and 3. The stasis was so severe that a considerable degree of tubular necrosis must inevitably have developed had the child lived a little longer. It is significant that in this case, where the clinicians' attention had been focussed on renal function by the earlier occurrence of oedema, apparently normal urine is known to have been passed at least up till two days before death, thus supporting the view that the renal lesion was recent.

In Case 2 also the degree of frank necrosis was slight in comparison with Cases 1 and 3 , though the glomerular lesion appeared similar in type and severity to that in the other cases. Here again it may be that the relative slightness of tubular necrosis was due to a short duration of the vascular upset; a point in favour of this is the absence of proliferative changes in the less damaged glomeruli in contrast to Cases 1 and 3. The considerable polymorph infiltration in and around the cortical tubules, on the other hand, suggests a lesion of longer duration; from analogy with the changes in infarcts in other organs (for example, the heart) one would not expect marked polymorph infiltration to appear in under twenty-four hours, by which time necrosis should be histologically obvious. It is possible, however, that the vascular upset may initially have been insufficient to produce frank tubular necrosis, but sufficient to produce emigration of leucocytes from the semi-static intertubular capillaries (the stage of leucodiapedesis or perileu-

PRINCIPAL CLINICAL FEATURES IN THIRTEEN. CASES OF SYMMETRICAL CORTICAL

\begin{tabular}{|c|c|c|c|c|c|c|c|}
\hline Year & Authors & $\begin{array}{c}\text { Age } \\
\text { (in years) }\end{array}$ & Sex & Associated Infection & $\begin{array}{c}\text { Anuria } \\
\text { (Days } \\
\text { Complete) }\end{array}$ & $\begin{array}{l}\text { Abnormal } \\
\text { Urine }\end{array}$ & $\begin{array}{l}\text { Renal } \\
\text { Pain }\end{array}$ \\
\hline 1913 & Herzog & 10 & F. & Peritonitis (cryptogenic) & $?$ & $?$ & $?$ \\
\hline 1915 & Zanzig & 14 & F. & Pneumonia & 4 & + & $?$ \\
\hline 1925 & Fahr & 4 & M. & $?$ & $?$ & $?$ & $?$ \\
\hline 1925 & Fahr & $?$ & $?$ & $?$ & $?$ & $?$ & $?$ \\
\hline 1928 & $\begin{array}{l}\text { Apert and } \\
\text { Bach }\end{array}$ & $13 \frac{1}{2}$ & M. & $\begin{array}{l}\text { Pulm. tuberculosis } \\
\text { Rhinopharyngitis }\end{array}$ & 2 & + & $?$ \\
\hline 1933 & Von Zalka & 13 & F. & Acute tonsillitis & 10 & + & + \\
\hline 1937 & Bell & 9 & M. & Pneumonia; empyema & - & $?$ & $?$ \\
\hline 1941 & $\begin{array}{l}\text { Dunn and } \\
\text { Montgomery }\end{array}$ & 9 & $\mathbf{M}$. & $\begin{array}{l}\text { Acute tonsillitis } \\
\text { (Scarlet fever) }\end{array}$ & 6 & $?$ & $?$ \\
\hline 1941 & $\begin{array}{l}\text { Dunn and } \\
\text { Montgomery }\end{array}$ & 8 & F. & $?$ & 4 & $?$ & + \\
\hline 1949 & $\begin{array}{l}\text { Authors' } \\
\text { Case I }\end{array}$ & $10 \frac{1}{2}$ & F. & Intestinal tuberculosis & 3 & + & - \\
\hline 1949 & $\begin{array}{l}\text { Authors' } \\
\text { Case II }\end{array}$ & $4 \frac{1}{2}$ & F. & $\begin{array}{l}\text { Streptococcal septicaemia } \\
\text { Arthritis : ? Meningitis }\end{array}$ & $?$ & $?$ & $?$ \\
\hline 1949 & $\begin{array}{l}\text { Authors' } \\
\text { Case III }\end{array}$ & $5 \frac{1}{2}$ months & F. & $\begin{array}{l}\text { Rhinopharyngitis } \\
\text { ' Gastroenteritis' }\end{array}$ & $?$ & $?$ & $?$ \\
\hline 1949 & $\begin{array}{l}\text { Authors' } \\
\text { Case IV }\end{array}$ & 9 weeks & M. & $\begin{array}{l}\text { Gastroenteritis } \\
\text { Otitis media } \\
\text { Bronchopneumonia }\end{array}$ & 1 & $?$ & $?$ \\
\hline
\end{tabular}


costasis in Ricker's (1921) schema of abnormal states of blood flow). After this change had been present for a day or more the vascular upset may have then become more severe, with more or less complete glomerular stasis, not present long enough to make the resultant tubular necrosis obvious in its full extent. Some degree of tubular necrosis was certainly present.

It may be objected that the well marked polymorph infiltration in Case 2 reflects not ischaemic damage, but a reaction to blood-borne infection. Haemolytic streptococci were isolated from the leptomeninges, and Gram-positive cocci were certainly present in the kidney sections, but they were found only in small groups within vascular lumina, without obvious reaction around them, indicating postmortem growth of organisms present in the blood at death. None' was found in the interstitial polymorph infiltrations. Further, the fact that polymorph infiltration was entirely absent from the medulla, though marked in the cortex, speaks strongly against a pyaemic infection of the kidney. It is unfortunate that the clinical record gives no help in assessing the duration of the renal lesion in this case; but severe diarrhoea came on suddenly four days before death, and there are grounds for believing that the renal and bowel lesions in such cases as this are contemporaneous.

\section{Clinical Features}

The principal clinical features in the thirteen cases of bilateral cortical necrosis of the kidneys in children under fifteen years of age are shown below. The symptoms are essentially the same as in adults. Unfortunately, most of the clinical records are incomplete. Fairly detailed clinical data are available in seven cases, those of Apert and Bach (1928), von Zalka (1933), two cases of Dunn and Montgomery (1941), and three of our cases.

NECROSIS OF THE KIDNEYS IN CHILDREN UNDER FIFTEEN YEARS OF AGE

\begin{tabular}{|c|c|c|c|c|c|c|c|c|}
\hline $\begin{array}{l}\text { Nitrogen } \\
\text { Retention }\end{array}$ & Blood Pressure & Oedema & Coma & Convulsions & Vomiting & Diarrhoea & Melaena & Various \\
\hline$?$ & $?$ & $?$ & $?$ & $?$ & + & $?$ & $?$ & \\
\hline$?$ & $?$ & $?$ & $?$ & $?$ & + & $?$ & $?$ & \\
\hline$?$ & $?$ & $?$ & $?$ & $?$ & $?$ & + & $?$ & \\
\hline$?$ & $?$ & $?$ & $?$ & $?$ & $?$ & + & $?$ & \\
\hline $\begin{array}{l}\text { Urea } \\
290 \mathrm{mg} . \%\end{array}$ & $?$ & + & $?$ & - & + & + & $?$ & Epistaxis \\
\hline $\begin{array}{l}\text { N.P.N. } \\
324 \text { mg. \% }\end{array}$ & $100 \mathrm{~mm} . \mathrm{Hg}$ & - & - & + & + & $?$ & $?$ & \\
\hline $\begin{array}{l}\text { Urea N. } \\
182 \mathrm{mg} \text {. }\end{array}$ & $120 \mathrm{~mm} . \mathrm{Hg}$ & - & $?$ & $?$ & $?$ & $?$ & $?$ & \\
\hline $\begin{array}{l}\text { Urea } \\
230 \mathrm{mg} . \%\end{array}$ & $140 / 80 \mathrm{~mm} . \mathrm{Hg}$ & + & - & - & $?$ & $?$ & $?$ & \\
\hline$?$ & $?$ & - & - & - & $?$ & + & $?$ & \\
\hline $\begin{array}{l}\text { Urea N. } \\
130 \mathrm{mg} . \%\end{array}$ & $120 / 70 \mathrm{~mm} . \mathrm{Hg}$ & - & + & + & + & + & + & \\
\hline$?$ & $?$ & $?$ & $?$ & $?$ & $?$ & + & $?$ & \\
\hline $\begin{array}{l}\text { Urea N. } \\
265 \mathrm{mg} . \%\end{array}$ & $?$ & + & - & + & + & + & + & $\begin{array}{l}\text { Hypo- } \\
\text { plastic } \\
\text { anaemia } \\
\text { (severe) }\end{array}$ \\
\hline$?$ & $?$ & + & - & - & + & + & - & \\
\hline
\end{tabular}


Fragmentary clinical notes are available in four cases, those of Herzog (1913), Bell (1937), Zanzig (1915), and one of our cases. No clinical notes are available in Fahr's (1925) two cases. Fahr described the pathology in the case of a boy of four years without giving any clinical data, and he mentioned having also seen a case in another child with 'dysentery.'

Infection. This was a feature in nine of the thirteen cases, and it may have been present in some of the other four. It was acute in seven patients, five of whom had a severe infection, and chronic in two.

Severe acute parenteral infection was a feature in five-patients; three had acute haemolytic streptococal infection, one had pneumonia, and one had pneumonia followed by empyema. Acute rhinopharyngitis was observed in our Case 3 on the day on which diarrhoea with melaena developed and eight days before death from renal failure. Apert and Bach's patient who had pulmonary tuberculosis developed rhinopharyngitis sixteen days before the detection of the urinary disturbance. Infective gastro-enteritis appeared to be the cause of the diarrhoea and deterioration in health which developed one month before death in our Case 4.

Chronic infection in the form of tuberculosis was a feature in two cases. One had a pulmonary infection and the other an intestinal infection. The tuberculous process in the latter case was relatively inactive (Case 1).

Infective enteritis was presumed in three patients of the series of thirteen. Fahr's two children were said to have 'dysentery', and our $5 \frac{1}{2}$ months' old infant ' gastro-enteritis.' 'But the diarrhoea in these cases may not have had an.infective origin, since diarrhoea, which is sometimes associated with melaena, is a common feature in patients with symmetrical cortical necrosis of the kidneys (Cases 1 and 3). Enteritis was not presumed in the second case of Dunn and Montgomery, 'a girl of eight years, previously quite healthy, who had a sudden attack of diarrhoea while out walking and developed anuria on the same day.' Such a history is more suggestive of a common cause for both the diarrhoea and the anuria than of an infective enteritis.

Urine. Attention was first drawn to the urinary abnormality by the development of oliguria, anuria, or haematuria, usually one of the first two. Abnormal urine, containing blood and albumin, was usually not observed until a small amount of urine was obtained by catheterization. In the six cases in which particulars about the urine are available the duration of anuria varied from two to ten days with an average of five days. In the two infants recorded in this paper it was not possible to be sure of the presence of anuria since both had diarrhoea, but oliguria was undoubtedly present (Cases 3 and 4). Data regarding urine examination are available in three cases. All showed haematuria and heavy albuminuria.
Renal pain. Pain in the kidney region was noted in two cases. Apparently it was not a notable feature in the other four cases with a reasonable history, although, of course, children often do not complain of pain.

Nitrogen retention. Blood nitrogen estimations were done in six cases and all showed very high levels. The figures varied from urea $230 \mathrm{mg}$. per cent. to urea nitrogen $265 \mathrm{mg}$. per cent.

Blood pressire. This was estimated in four cases. It was normal in one, slightly elevated in two and considerably elevated in one.

Oederen. This feature was present in four and not apparent in four cases.

Headache. This symptom was not mentioned in any case, but it may, nevertheless, have occurred since children usually do not complain of it.

Coma. The sensorium remained clear in five cases until death, but one child developed coma on the day before death.

Convulsions. Fits or muscular twitchings were observed in three of the seven cases with a fairly detailed history. Our patient aged $10 \frac{1}{2}$ years developed major convulsions with coma the day before death. Von Zalka's patient died in a terminal convulsion. In this disease convulsions are a grave sign and indicate impending death.

Voniting. This was a feature in seven cases, including our infant who' suffered from gastroenteritis.

Diarrhoea. This symptom occurred in eight cases, including our infant with gastro-enteritis and Fahr's two cases about which no other clinical facts are known.

Melaen. Blood was observed in the stools in two of the six cases with diarrhoea in which there is a reasonable history (our Cases 1 and 4). It began at the same time as the diarrhoea in our patient of $10 \frac{1}{2}$ years in whom there was no evidence of alimentary infection other than healing tuberculosis. It also occurred on the first day of illness and

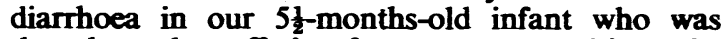
thought to be suffering from gastro-enteritis. The occurrence of alimentary haemorrhage in renal cortical necrosis seems worthy of emphasis in view of the probability that it is of similar pathogenesis to the renal lesion.

\section{Discussion}

The renal lesion. The pathogenesis of symmetrical renal cortical necrosis has been fully discussed by numerous authors, notably Scriver and Oertel (1930), Dunn and Montgomery (1941), and Duff and More (1941). It is generally agreed that the essential feature is reduction or cessation of blood flow through the glomeruli, the necrosis following as a result of the ischaemia of the cortex thus produced. Many of the earlier authors laid stress on the primary rôle of thrombosis, but others have, in our opinion, correctly, regarded it as secondary to stasis. And in some cases (Dunn and Montgomery, 1941; Duff and More, 1941) the 
degree of thrombosis has been inadequate to explain the widespread stasis.

Those who discard thrombosis as the primary phenomenon postulate various functional vascular disturbances as the cause of the stasis. Dunn and Montgomery suggested that the primary fault is a dilatation of the glomerular capillaries, either from toxaemia of some kind or from anoxia associated with general hypotension; this dilatation produces excessive glomerular filtration, which raises the viscosity of the blood within the capillaries to such a degree that glomerular stasis occurs. The dilatation and the various structural changes found in the afferent arterioles and interlobular arteries are, in their opinion, secondary, being due to the rise of pressure in these vessels following occlusion of the related glomerular capillary bed. They supported this conception by the fact that the glomerular capillaries are unique among capillaries because of their normal function of filtration, whereas the renal arteries and arterioles are functionally similar to those of other organs. It is not, however, safe to assume that the renal arteries and arterioles behave as do those of other organs; the work of Lauson, Bradley, and Cournand (1944), Corcoran, Taylor, and Page (1943), and Trueta and his fellow workers (1947) indicates an especial tendency of the renal arteries to very active constriction under certain circumstances. Further, the associated lesions found fairly frequently in other organs in cases of cortical necrosis strongly suggest in our opinion a pathogenesis similar to that of the renal lesions; and the capillary bed of these organs does not share the peculiar function of the glomerular capillaries.

Scriver and Oertel (1930), also, explained the production of the lesions by a-process of vascular dilatation with resultant stasis, without, however, limiting the primary vascular change to the glomeruli. They applied to the pathogenesis of the cortical necrosis the concept of Ricker and his school (Ricker and Regendanz, 1921). This concept, based on direct observation of the vascular reactions to various stimuli in experimental animals, implies that small arteries and capillaries respond to stimuli of varying intensity by a series of different reactions, namely, (a) dilatation with acceleration of the stream; (b) constriction with slowing; (c) great dilatation with, eventually, slowing and perhaps complete stasis, the slowing and stasis being due to constriction of the arteries proximal to the strongly stimulated area. Stasis, during which the red cells become packed together, but not necessarily thrombosed, may be reversible. The stages of dilatation with sluggish flow which may precede or follow stasis are both described as peristasis. During this stage of peristasis diapedesis of red cells and leucocytes may occur, though not at the same point in the stage. This concept does not seem to have attracted the interest it deserves among British pathologists. It has been criticized, notably by Tannenberg (1925), who stressed the importance of chemical changes in the irritated tissue,-producing a local sedimenting tendency of the intravascular red cells and thereby leading to stasis without necessarily any change in vascular calibre. Such local chemical changes would also cause leucocytic emigration by chemotaxis.

Much of Tannenberg's criticism appears valid. But the experimental observation of graded vascular reactions on the lines of Ricker's concept remains, and there are certainly lesions in human pathology where primary vascular dysfunction seems most probable, complicated no doubt by secondary effects produced by extravascular chemical change. Renal cortical necrosis seems to be such a lesion. Whether the pattern of vascular change fits in to the grading of Ricker's concept is, however, another matter.

Scriver and Oertel explained the changes in cortical necrosis on the basis of Ricker's thesis. They postulated a vasoparalysis, with great vascular dilatation, affecting the 'terminal arterial segments' (the smallest arteries, the arterioles, and the arterial capillaries), " to which is generally added narrowing in the course of the preceding proximal artery.' The resultant stasis leads to necrosis. The leucocytic emigration, which may be present both in the non-necrotic and the necrotic areas of the cortex, occurs during the preceding stage of peristasis. They did not believe that vasospasm was the primary disturbance; the capillary congestion and red cell diapedesis were, in their opinion, too pronounced.

It has long been known that renal cortical necrosis can be produced in rabbits by the administration of staphylococcal toxin. De Navasquez (1938) investigated this rabbit lesion. He believed that the earliest change was great vascular dilatation of the interlobular arteries and afferent arterioles. This led to a rise of pressure in the glomerular capillaries producing increased glomerular filtration, red cell concentration in the capillaries, conglutination, and stasis. This theory has much in common with that of Dunn and Montgomery, but locates the primary vasodilatation in the arteries and arterioles rather than in the glomerular capillaries.

Other workers (Jardine and Teacher, 1911 ; Ash, 1933; Hertig and Mallory, 1946; and others) believe that the primary disturbance is spasm of renal arteries or arterioles. This gains experimental support from the work of Byrom (1937) who produced similar renal lesions in rats by injections of vasopressin; in these experiments marked focal blanching of the surface of the kidneys was seen shortly after injection. Byrom described the widespread cortical necroses he produced as anaemic infarcts, but he noted that some capillaries showed dilatation. It is difficult to say from his description whether glomerular capillary dilatation was present to a degree sufficient to make his lesions entirely comparable to human cortical necrosis.

The vasospastic theory is strongly supported by the fact that very active arterial contraction is a notable characteristic of the kidneys under various pathological conditions. Corcoran, Taylor, and Page (1943), and Lauson, Bradley, and Cournand 
(1944) have shown, in the dog and in man respectively, that in traumatic shock the effective renal blood flow is reduced out of proportion to the degree of hypotension, and may remain reduced though the blood pressure has been restored to normal. In heart failure, with reduced cardiac output, Mokotoff, Rose, and Leiter (1948) have shown that effective renal blood flow is reduced to a much greater extent than the cardiac output, indicating greater vasoconstriction in the kidneys than in the body as a whole.

Trueta and his fellow workers (1947) have demonstrated this renal vasoconstrictor phenomenon with great precision in the rabbit. They have shown that various stimuli will cause a shunting of the renal blood flow away from the cortex, making it almost medullary, apparently by intense vasoconstriction of the distal parts of the interlobular arteries. The route of the medullary flow is through the juxta-medullary glomeruli, supplied from the proximal parts of these arteries. They suggested that renal cortical necrosis in man may be due to a prolonged and exaggerated version of this shunt phenomenon. They emphasized the striking fact that in the human lesion not only is the medulla spared the necrosis that devastates the cortex, but also the juxta-medullary glomeruli are much less severely affected than those throughout the rest of the cortex. And they have shown that staphylococcal toxin, notorious as a means of producing cortical necrosis in the rabbit, calls the medullary shunt into action. On direct inspection, the surface of the rabbit's kidney was seen to blanch shortly after the intravenous injection of the toxin.

Duff and More (writing in 1941, before the publication of the monograph of Trueta and his fellow workers) attempted to resolve the conflict between the vasoparalytic and vasospastic theories by a compromise. They postulated a state of excessive sensitivity of renal arteries and arterioles in those individuals who develop cortical necrosis. Various stimuli may then produce in these hypersensitive vessels a series of vascular disturbances of increasing severity: intense vasospasm, vasoparalysis, damage to the arterial walls either from the vasospasm or from direct action of some toxic substance. At any stage in this sequence blood flow may be halted, either from thrombosis, or blood stasis and conglutination following vasoparalysis, or from intense vasoconstriction alone.

This interpretation seems to explain the lesion most satisfactorily, provided that (especially in view of the work of Byrom and of Trueta et al.) we accept spasm of the interlobular arteries as the essential initial phenomenon. By the time the patient dies these vessels, as well as the afferent arterioles and the glomerular capillaries, usually appear to be in a state of vasoparalysis. This is probably due to anoxic damage to the vessel walls incurred during the initial vasoconstriction, reinforced perhaps by a toxin, though in some cases evidence of a primary toxaemia is singularly lacking. Probably the factor, stressed by De Navasquez (1938) and by Dunn and Montgomery (1941), of excessive glomerular filtration, leading to increased viscosity of the blood in the glomerular capillaries, plays a part in the final production of glomerular stasis. If arterial vasospasm passes off blood will re-enter glomeruli whose capillaries, damaged by the period of vasospastic anoxia, will presumably allow excessive filtration to take place, until the capillary flow is brought to a standstill by red cell conglutination or thrombosis.

Dunn and Montgomery regarded thrombosis of renal veins as another mechanism capable of producing the lesion. They cited cases recorded by Torrens (1911), Herzog (1913), and Fahr (1925). But analysis of these records does not suggest that the lesions present were really examples of symmetrical renal cortical necrosis. Herzog and Fahr described necrosis in the medulla as well as the cortex in their cases, which in our opinion eliminates them from this category. In the case reported by Torrens the histological description given is too brief to permit of its proper classification.

Lesions in other organs. These fall into two groups, 'associated lesions,' apparently contemporaneous with that of the kidneys, and probably produced by a similar mochanism, and ' background lesions' indicating pre-existing diseases of which the renal cortical necrosis may have been a complication.

Associated lesions. The lesions in our cases which may be regarded as contemporaneous were the haemorrhagic necrosis of the ileum in Case 1 and of the colon in Case 2, and the focal necroses of the liver in Case 4 . Both have been previously described in the literature of symmetrical renal cortical necrosis. Haemorrhagic and necrotizing lesions of the alimentary tract have been recorded with rather striking frequency, in the oesophagus (Weaver and von Haam, 1939), stomach (Herzog, 1913), small intestine (zu Jeddeloh, 1932), and colon (Jardine and Teacher, 1911; Herzog, 1913 : Bamforth, 1923; Scriver and Oertel, 1930; Dunn and Montgomery, 1941; Sheldon and Hertig, 1942) And in other cases, 'dysentery' or 'bloody diarrhoea' has been noted clinically, without mention being made of the state of the bowel at necropsy. In some of these cases it has been suggested either that the bowel lesion has been the primary one, later causing the renal cortical necrosis, or that the bowel lesion has been a "uraemic colitis " following the establishment of renal failure. It is difficult to eliminate either of these hypotheses from the published data of the individual cases, but in some at least the history is more suggestive of a simultaneous onset of the lesions in kidneys and bowel. Certainly in Case 1 of our series this appeared to be so; anuria was observed on the morning after the onset of bloodstained diarrhoea, and microscopically the ages of the renal lesion and the haemorrhagic enteritis appeared similar. 
The fact that the bowel lesions appear to have arisen simultaneously with those in the kidneys suggests that they are of similar pathogenesis; that is, due to local vascular disturbance. This is borne out pathologically. In our Case 1 the patches of 'enteritis' showed a predominance of necrosis and vascular change, (congestion, oedema, haemorrhage, and thrombosis), over leucocytic reaction. In Case 4 the appearance of the lesion of the colon was that of a massive haemorrhagic infarction suggesting a thrombosis of the inferior mesenteric artery, but no such thrombosis could be found. Arterial vasospasm would seem to be the most probable basic factor in the production of these lesions, as of those in the kidneys.

Our fourth case showed small focal necroses in the liver. These also have been recorded not infrequently (Bamforth, 1923; von Zalka, 1933; Garvin and Van Wezel, 1938; Weaver and von Haam, 1939; Sheldon and Hertig, 1942; Brown and Crane, 1943). These focal necroses have been described variously as centrilobular, central and midzonal, diffuse, or typically eclamptic. In our case they were haphazard. Microscopically they appeared to be contemporary with the renal lesion. Their haphazard distribution can, in our opinion, best be explained on a basis of local arteriolar spasm. Focal necroses due to toxaemia or to generalized anoxia or ischaemia should have shown a more constantly zonal distribution. The development of jaundice in this case the day before death suggests a degree of liver failure greater than could be explained by the focal necroses alone; these were sparse, and the total amount of liver tissue involved musst have been trivial. We have no means of knowing whether the jaundice was due to widespread ischaemia of the liver, produced by extensive arterial or arteriolar spasm, reaching an intensity sufficient to produce necrosis only in the territories of a few arterioles; to ischaemia from general hypotension; to some hypothetical toxaemia; or to prolonged nutritional deficiency. The liver showed no histological signs of diffuse damage, such as fatty degeneration.

Other organs have been noted in the literature of cortical necrosis as showing lesions such as might well have been produced by arterial or arteriolar spasm. Focal necroses have been reported in the adrenals (Jardine and Teacher, 1911; Evans and Gilbert, 1936; Weaver and von Haam, 1939; Sheldon and Hertig, 1942; Hertig and Mallory, 1946); in the spleen (Geipel, 1925; Scriver and Oertel, 1930); in the pancreas (French, 1940); and in the hypophysis (Sheldon and Hertig; Doniach and Walker, 1946). The hypophyseal necroses occurred in cases complicating pregnancy, and may be explained as examples of the lesion found not uncommonly in the post-partum state. Apart from these lesions in the hypophysis, the associated lesions have been confined to and distributed widely through the splanchnic vascular bed.

These associated and probably contemporaneous lesions merit more attention than they have received, since they may play a considerable part in, or even dominate, the clinical picture. In our Case 1 the bowel lesion was the first sign of catastrophe, and in Case 2 it was of such severity that it must almost certainly have caused symptoms, though the clinical notes unfortunately give inadequate details of the terminal illness. In Case 4 liver damage rather than kidney damage marked the onset of the terminal syndrome, since jaundice developed whereas no urinary disturbance was noted.

We suggest, therefore, the concept of a ' syndrome of splanchnic vasospasm,' rather than one of a purely renal disturbance. It is convenient to use the designation ' symmetrical renal cortical necrosis,' since the renal lesion appears to be a constant part of the syndrome, and may be the only obvious component. But the wider concept should be borne in mind, since both clinically, and macroscopically at necropsy, the renal lesion may not make itself obvious in early cases, or may be overshadowed by other components of the syndrome.

BACKGROUND DISEASES. Infection which could be presumed to antedate the renal lesion was present in three of our own four cases (see table). It was of varying kind and degree: most severe in Case 2 (haemolytic streptococcal arthritis and septicaemia); fairly severe in Case 4 (infantile gastro-enteritis, purulent otitis media, and broncho-pneumonia); and mild in Case 1 (abdominal tuberculosis of low grade activity). In Case 3 rhinopharyngitis was noted at the onset of the illness, but this appeared to be an insignificant infection. The clinical diagnosis of gastro-enteritis appears doubtful ; blood in the stools was noted on the first day of diarrhoea, which is unusual in true infective infantile gastro-enteritis. It seems probable that the 'enteritic' symptoms were due to minor vasospastic incidents in the bowel, contemporaneous with, rather than causing, the renal lesion. The significance of the hypoplastic anaemia which was present in this case is not clear. We have no evidence that it antedated the renal lesion. It may be, therefore, that this case falls into the idiopathic group (vide infra).

In the other cases in childhood which we have briefly reviewed (see table) infection was present in most, but again it was of varying type and severity. In the two cases reported by Fahr as complicating ' dysentery,' the bowel lesion may well have been contemporaneous with that of the kidneys, both being components of a splanchnic vasospastic syndrome.

A review of the adult cases in the literature shows a remarkable diversity of background diseases. Termination of pregnancy, usually complicated by eclampsia, or retroplacental haemorrhage, or both, stands out as the commonest cause. Another large group has been associated with infections of various kinds. A miscellaneous group has been associated with such diverse conditions as myocardial infarction (von Zalka, 1933), traumatic shock (Furtwängler, 
1927; McFarlane, 1941), burns (Brown and Crane, 1943), polyarteritis nodosa (Mallory, 1947), carcinoma of ureter (Dunn and Montgomery, 1941), carcinoma of prostate (Weber, 1909; Fahr, 1925), and poisoning by dioxan (Barber, 1934), and almond extract (Garvin and Van Wezel, 1938). A few cases have occurred without evidence of any primary disease (Ash, 1933; Garvin and Van Wezel, 1938; personal observation (Campbell, unpublished). In the case attributed by French (1940) to acute pancreatitis, it seems possible that this condition, regarded as primary, was in fact an associated contemporaneous lesion rather than the cause of the renal lesion.

Dunn and Montgomery suggested that two main factors could be extracted from the diverse etiological background: (1) an acute fall in blood pressure, and (2) a toxic factor, bacterial or otherwise. They stressed the hypotension or relative hypotension produced by the occurrence of retroplacental haemorrhage in the previously hypertensive eclamptic woman, the usual background of the pregnancy cases. We do not agree with their theory that these factors act primarily on the glomerular capillaries, but the two factors do appear to be the most probable etiological common denominators. In those cases complicating infections bacterial toxaemia may be postulated as the prime cause, whereas in some at least of the miscellaneous group acute hypotension seems to be responsible (for example, the cases complicating myocardial infarction, traumatic shock and burns). In view of the work of Trueta et al. (1947), Corcoran et al. (1943), and Lauson et al. (1944), both these factors seem capable of calling into action renal cortical vasospasm, and the simultaneous vasospasm which we believe may occur in other parts of the splanchnic vascular bed.

The idiopathic cases remain unexplained. As Duff and More emphasized, an essential factor in the etiology of the condition appears to be an unusual degree of sensitivity of the renal cortical vessels. Renal cortical necrosis occurs in only a small proportion of those individuals who suffer from the various primary diseases recorded. In certain individuals the sensitivity of the renal cortical arteries appears to be so great that a stimulus too slight to be associated with any obvious primary disease may call the renal medullary shunt into violent and prolonged action.

Special features in childhood. From our review of the literature there is no doubt that renal cortical necrosis, which is fairly rare in adults, is also rare in children. No definite cases have previously been recorded in infants, though two doubtful examples have been mentioned: the first was an infant aged 11 months, briefly mentioned by Fahr (1925), and not identified by him as renal cortical necrosis; the second was an infant aged $3 \frac{1}{2}$ months, mentioned by Bell (1937). In a brief note on this infant Bell reported a renal lesion characterized by widespread thrombosis of afferent arterioles. The state of the tubules was not mentioned. He did not classify this case as symmetrical cortical necrosis, though he noted its resemblance to the case of Juhel-Rénoy. It may possibly belong to this category, but satisfactory classification is impossible in the absence of sufficient detail. It seems to us that in infancy the lesion may occasionally be missed. Clinically, oliguria or anuria are less obvious in the napkin period, and pathologically, the renal lesion (our Case 4) may not be macroscopically striking at this age. Furthermore, the peculiarities of the infant kidney may modify the pathological lesion to a much less florid picture. In our Case 4, despite gross glomerular stasis, tubular necrosis was inconspicuous. This may have been merely a matter of the immaturity of the lesion. But in infancy, tubular development lags anatomically behind glomerular development, and the work of McCance (1946) and Dean and McCance (1947) suggests that in this age period tubular function also lags behind that of the glomeruli. The relatively undeveloped tubules of the infant kidney may well be less vulnerable to ischaemia than those of the kidney whose function has achieved the adult pattern, and tubular necrosis may therefore tend to be less conspicuous in the infant. Nevertheless, that it can occur on a large scale as early as five months, is shown by our Case 3.

The acute pneumococcal nephritis reported by Blackman and Rake (1932) as occurring especially in infants has certain resemblances to the lesion of renal cortical necrosis. These authors found fibrin and hyaline thrombosis constantly in the glomeruli, with a varying amount of necrosis of tubular epithelium. In many of their cases the changes appear to have been too slight to justify the assumption of the severe degree of glomerular stasis which is characteristic of renal cortical necrosis, but some cases at least suggest a mild form of that lesion. Indeed, it seems probable that from time to time cases, both in children and in adults, have been labelled 'acute thrombotic nephritis' or 'acute haemorrhagic nephritis' which in essence have been cases of symmetrical renal cortical necrosis.

\section{Summary}

The clinical and pathological features of symmetrical renal cortical necrosis in childhood have been reviewed.

Four personal cases are described, including two cases in infants, the first to be recorded in this age period. Nine other cases occurring in children under fifteen years of age have been found in the literature, and have been reviewed.

The clinical features of the disease in childhood are similar to those of cases in adult life. Anuric or oliguric renal failure is the predominant feature. But the occurrence of vascular disturbances in other parts of the splanchnic vascular bed is emphasized, 
notably in the bowel; diarrhoea, with or without passage of blood, is a frequent symptom. The renal lesion is regarded as the predominant feature of a splanchnic vasospastic syndrome.

We are indebted to Dr. Alexander Joe for permission to use the clinical records of two cases, and to Mr. T. C. Dodds for the photographs.

\section{REFERENCES}

Apert, M. E., and Bach, E. (1928). Bull. mém. Soc. méd. hôp. de Paris, 52, 471.

Ash, J. E. (1933). Amer. J. med. Sci., 185, 71.

Bamforth, J. (1923). J. Path. Bact., 26, 40.

Barber, H. (1934). Guy's Hosp. Rep., 84, 267.

Bell, E. T. (1937). Amer. J. Path., 13, 497.

Blackman, S. S., and Rake, G. (1932). Bull. Johns Hopk. Hosp., 51, 217.

Brown, C. E., and Crane, G. L. (1943). J. Amer. med. Ass., $122,871$.

Byrom, F. B. (1937). J. Path. Bact., 45, 1.

Corcoran, A. C., Taylor, R. D., and Page, I. H. (1943). Ann. Surg., 118, 871.

Dean, R. F. A., and McCance, R. A. (1947). J. Physiol., 106, 431.

De Navasquez, S. (1938). J. Path. Bact., 46, 47.

Doniach, I., and Walker, A. H. C. (1946). J. Obstet. Gynaec., 53, 140.

Duff, G. L., and More, R. H. (1941). Amer. J. med. Sci., 201, 428.

Dunn, J. S., and Montgomery, G. L. (1941). J. Path. Bact., 52, 1.

Evans, N., and Gilbert, E. W. (1936). . Amer. J. Path., $12,553$.
Fahr, T. (1925). Henke and Lubarsch's Handbuch der speziellen pathologischen Anatomie und Histologie, vol. VI/I, pp. 132, 140, and 143. Berlin. Springer.

French, R. W. (1940). Amer. J. Surg., 47, 666.

Furtwängler, A. (1927). Quoted by Duff and Murray.

Garvin, C. F., and Van Wezel, N. (1938). Arch. intern. Med., 62, 423.

Geipel, P. (1925). Arch. Gynäk., 124, 231.

Hertig, A. T., and Mallory, T. B. (1946). New Engl. J. Med., 234, 416.

Herzog, G. (1913). Beitr. path. Anat., 56, 175.

Jardine, R., and Teacher, J. H. (1911). J. Path. Bact., $15,137$.

Juhel-Rénoy, E. (1886). Arch. gén. Méd., 17, 385.

Lauson, H. D., Bradley, S. E., and Cournand, A. (1944). J. clin. Invest., 23, 381 .

Mallory, T. B. (1947). New Eng. J. Med., 236, 670.

McCance, R. A. (1946). Schweiz. med. Wschr., 76, 857.

McFarlane, D. (1941). J. Path. Bact., 52, 406.

Mokotoff, R., Ross, G., and Leiter, L. (1948). J. clin. Invest., $27,1$.

Ricker, G., and Regendanz, P. (1921). Arch. path. Anat., 231, 1.

Scriver, W. de M., and Oertel, H. (1930). J. Path. Bact., 33, 1071.

Sheldon, W. H., and Hertig, A. T. (1942). Arch. Path., $34,866$.

Tannenberg, J. (1925). Frankfurt. Z. Path., 31, 173, 182, 285,351 and 385.

Torrens, J. A. (1911). Lancet, 1, 99.

Trueta, J., Barclay, A. E., Franklin, K. J., Daniel, P. M., and Prichard, M. M. L. (1947). Studies of the Renal Circulation. Oxford. Blackwell.

Von Zalka, E. (1933). Arch. path. Anat., $290,53$.

Weaver, R. G., and von Haam, E. (1939). Arch. intern. Med., 63, 1084.

Weber, F. P. (1909). Lancet, 1, 601.

Zanzig. T. (1915). Quoted by Duff and Murray.

zu Jeddeloh, B. (1932). Arch. path. Anat., 286, 389. 